Revista de la red interuniversitaria de estudios sobre las literaturas rioplatenses contemporáneas en Francia

7 | 2012

Arqueologías

\title{
La memoria infiel
}

Juan José Becerra

URL: http://journals.openedition.org/lirico/752

DOI: $10.4000 /$ lirico.752

ISSN: 2262-8339

Editor

Réseau interuniversitaire d'étude des littératures contemporaines du Río de la Plata

\section{Referencia electrónica}

Juan José Becerra, «La memoria infiel », Cuadernos LIRICO [En línea], 7 | 2012, Publicado el 11 octubre 2012, consultado el 22 septiembre 2020. URL : http://journals.openedition.org/lirico/752 ; DOI https://doi.org/10.4000/lirico.752

Este documento fue generado automáticamente el 22 septiembre 2020

\section{(c) $(1) \Theta \Theta$}

Cuadernos LIRICO está distribuido bajo una Licencia Creative Commons Atribución-NoComercialSinDerivar 4.0 Internacional. 


\section{La memoria infiel}

Juan José Becerra

\section{REFERENCIA}

Levrero, Mario, El alma de Gardel, Buenos Aires, Mondadori, 2012, 119 p. 
1 La primera edición de El alma del Gardel, de Mario Levrero (1940-2004), apareció en Montevideo en 1996, once años después del estreno de Gardel, el alma que canta, una película documental dirigida por Carlos Orgambide y producida por el cantante Ramón "Palito" Ortega, en la que el caricaturista Hermenegildo Sábat, el jockey Irineo Leguisamo y el compositor Enrique Cadícamo, entre otras figuras del Río dela Plata, se refieren tanto a la destreza de Carlos Gardel para el canto como a su aura, además de desarrollar a coro una secuencia de anécdotas - alguna de ellas paranormales- que sobrealimentan su misterio.

La historia que cuenta Levrero en El alma de Gardel funciona como el laboratorio de sus títulos más célebres: El discurso vacío (también de 1996) y La novela luminosa, libro póstumo y obra cumbre publicada en

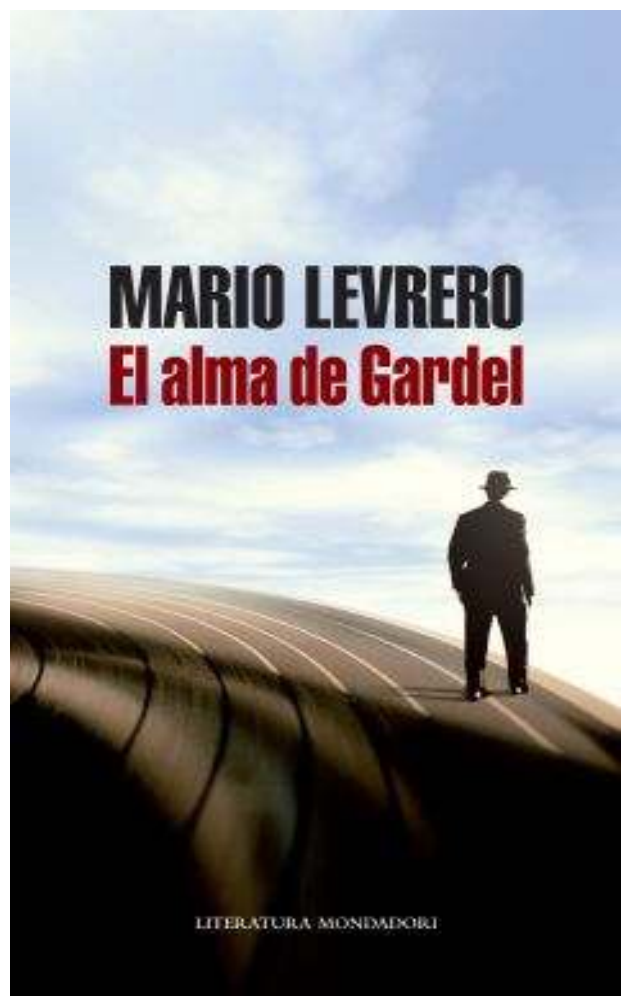
2005. Allí el narrador es objeto y testigo de una serie de peripecias que no alcanzan el status exterior de lo que podemos llamar "aventuras" porque se trata en gran parte de una aventura interior. En la primera escena hurta un paraguas de una biblioteca. Lo sigue un hombre, quien encarna "el alma de Gardel" y se manifiesta como una fuerza física que primero llama a su puerta y posteriormente lo centrifuga y lo hace levitar en el dormitorio. Luego se suceden series de encadenamientos mentales (llamémoslos, sin temor, "la trama") que pueden resumirse como una experiencia reflexiva acerca de la composición del recuerdo, lo que opera como una fuente de especulaciones que pone en marcha la narración intensiva de Levrero, a contracorriente del carácter expansivo del género.

3 Sobre el final, el narrador, que va descubriendo su mundo interior mediante la contemplación de la dinámica urbana (cuya variedad le hace exclamar: "Cuántos mundos"), una especie de etnografía espontánea que le sirve para distinguirse en el conjunto, a la que le agrega algo que no es otra cosa que paciencia, el insumo principal de la poética de Levrero, se descubre cuál es el libro que en algún momento de la historia intenta encontrar en las librerías: "Memoria y percepción". El libro - del que no se refiere ni siquiera el nombre de un autor falso- no existe, pero si existiera es más que evidente que sería Henri Bergson.

4 Eso que hemos llamado "la trama" para no perdernos es, en El alma de Gardel, una multiplicidad de pequeños elementos combinados, muchas veces de manera inconsecuente o siguiendo líneas causales quebradizas. En primer lugar (he aquí el primer elemento de varias novelas de Levrero), el narrador, un investigador de la obra de Gardel que no se anima a llamarse a sí mismo escritor ("hay pocos escritores en el mundo que merezcan ese nombre"), quizás porque en su propio régimen encaja mejor como un personaje solitario que no teme asumir su misantropía y que se vincula 
mediante incidentes con otros personajes, de los que absorbe toda la energía dramática que hace funcionar su romanticismo.

5 Estos personajes pueden tener, por un lado, un carácter doble, como el señor Caorsi, un desconocido con quien el narrador juega al ajedrez, y que cambiará de nombre y figura dos veces a lo largo del relato (una concesión a ese otro mundo que tienta a Levrero en todos sus libros : un mundo de perfiles fantásticos que convive con la realidad básica, es decir la realidad acordada) ; y por el otro, las mujeres, un elenco más bien gaseoso que se manifiesta en forma de recuerdos o fantasmas aun cuando, como en el caso de Verónica, una supuesta sobrina muy joven de la que el narrador se enamora, se presenten mediante un vínculo de actualidad, contemporáneo de una escritura que tiene algo de un diario que recoge menos los testimionios de una actividad vital que los de una sensibilidad. Levrero exprime los actos de sus personajes y trabaja con lo que queda de ellos, una materia residual muy parecida al conocimiento que sucede a la experiencia, en este caso la experiencia inmóvil de sentir. Conocer, para Levrero, es detener la experiencia y exponerla mediante las reglas de una actividad laboratorista ; es decir, tomar pruebas de la experiencia vital reducida a los fenómenos de la percepción (la extracción, el hisopado, el sondeo, el buceo escópico, son sus "métodos" de aproximación) y traducirla a unos pocos resultados que, para hacerle honor a su ambigüedad, debemos llamar "variables". La literatura achica el tamaño de la experiencia pero a cambio de obtener su verdad más intensa: aquello que sucede, invisible, a la vista de todos.

6 Esas combinaciones se multiplican en una serie de escenarios sobre los que Levrero establece deslizamientos de categorías sin que se noten los saltos. Tanto los planos de la percepción (sueño, vigilia, alucinación) como sus herramientas auxiliares (pensamientos, recuerdos) forman una misma materia narrativa dada por contigüidad o por asociaciones que responden del mismo modo, y con la misma obediencia, a los llamados de la lógica y el oscurantismo.

7 Debería recordarse que Mario Levrero publicó en 1978 Manual de parapsicología, y que la psicología "paralela" fue un discurso, entre otros, adoptado con franqueza durante la escritura de El discurso vacío. Además, es sabido que le dio mucha importancia a su lectura de Psicoanálisis del arte, de Charles Baudouin (1893-1963), un psicoanalista suizo que se inclinó hacia métodos heterodoxos como el autoconocimiento por medio de la autosugestión, ese tipo de exploración personal que hoy puede reconocerse como una de las vertientes de la autoayuda.

El libro de Baudouin, según él mismo lo ha manifestado en varias entrevistas, resume lo que Levrero piensa sobre la relación autor-lector, una relación "de alma a alma". Por esa razón - porque esa relación le parece posible- detesta la crítica que se interpone entre la conexión de ambas sensibilidades. El alma es para Levrero una unidad de sentido integral y constitutiva de varios de sus libros. Está presente en El alma de Gardel, por supuesto; y también en El discurso vacío, donde se describe el alma como un fenómeno de la percepción que no está dentro de lo que sería la carta de percepciones normales.

9 Las percepciones regladas, normalizadas, incluso enumeradas por el formato clasicista de los cinco sentidos, no convencen a Levrero como dispositivo capaz de recibir esa literatura ambiental que, al paracer, habría en la realidad, y de la que intenta extraer sus novelas. Para él hay un más allá que se puede percibir si se dispone de una antena novedosa : la antena que pueda captar la etología del novelista. Dicho de otro modo, el 
novelista es un animal del que vale la pena conocer sus hábitos cotidianos, mínimos y a la vez trascedentes, porque en ellos opera no un estilo (que Levrero detesta a punto de convertirlo en el tema de El discurso vacío) sino una percepción especial que en el momento de manifestarse ya es una literatura a la que sólo le falta ser trancripta.

El alma de Gardel, El discurso vacío y La novela luminosa son novelas que responden artísticamente a la falta de concentración. Hay una lucha que sostienen el deseo de escribir y su enemigo íntimo y público : el entorno. En ese entorno figuran la familia, la sociedad, las interrupciones originadas por el mundo exterior y todo aquello que Roland Barthes llamó, en La preparación de la novela, la "gestión", un sistema de compromisos ciudadanos que destruyen la unidad romántica del sujeto (y mucho más si ese sujeto se encuentra preparando una novela) y lo aparta de sus asuntos. Pero el drama mayor de escribir una novela - el drama mayor pero también todo lo que la novela puede aspirar a ser- consiste en la infidelidad de la memoria: "Qué garantía, pues, tendrá mi lector de la fidelidad de este relato que es, él, pura memoria y sólo memoria".

La memoria es la víctina de la desconcentración. Pero esa fatalidad es reparada por el entretanto del no sé qué hacer, el momento verdaderamente real de la escritura de ficción. Ese incidente constante, el de salirse de la vía por la que aparenta avanzar la novela, es la marca astrológica de Mario Levrero, para quien el acto de escribir no necesita un tema. Escribir sin tema es la experiencia normal de la escritura según Levrero. Hay un suspenso en sus novelas -nuestra expectativa ya no es qué va a ocurrir en la historia sino cómo va a quedar- que se asemeja a un trabajo de descomposición, como si al cabo de la lectura viésemos las novelas desarmadas, sometidas a un inventario en el que figuran las descripciones detalladas de cada una de las piezas que las compusieron. Las novelas de Levrero son hechos póstumos, posteriores a todas las etapas de la confección literaria. Imaginar y escribir una novela es una experiencia frívola si se la compara con la experiencia terminal de su volatilización, lo que sucede, entre el milagro y el terror, durante la lectura (como si leyéramos una nube).

El plan narrativo de Mario Levrero, si lo hubiere en un sentido positivo, lejos de la idea progresista de que para narrar hay que adelantarse, consiste en detenerse. Se trata de un suspenso intensivo y formalista: suspender equivale a conocer, a ganar tiempo para que la percepción fluya desde las profundidades de cada fenómeno acaecido y encuentre su forma. Si se observa con atención, veremos que El alma de Gardel es, al margen de sus pocos personajes, la historia de unos cuantos objetos : un paraguas rojo, un aviso de lencería, un libro y "un alma". Pero no son objetos recortados sino versiones difusas del mundo físico atravesado por el tiempo (o por su espejo deformante: la memoria), cuadros en los que el realismo alcanza sus confines y se entrega al poder de la alucinación. Detrás de cada objeto -nada más firme que un objeto - laten los espejismos de la experiencia, el pasado y el recuerdo, un menú de fantasmas que producen el delirio de ablandar el mundo físico y someterlo a la intermitencia.

13 En un pasaje de El alma de Gardel, el narrador de Mario Levrero - sin dudas una interposición directa del autor- ve caer la lluvia sobre el asfalto de Montevideo. La escena deriva en reflexiones teóricas: "Pero al final todo es agua que corre, todo es pensamiento que fluye, todo es literatura que se escribe o palabras que se piensan...". Indivisibles en el sistema de Levrero, la literatura y el pensamiento son materias escurridizas. Fijarlas es un gesto artístico que nos lleva directamente al fracaso, el único éxito al que la literatura podría aspirar. Esa inestabilidad, basada en el reconocimiento 
de identidades abiertas, géneros híbridos, discursos impuros, todo contemplado desde la inmovilidad o la pasividad sobre las que se monta la figura de un narrador sedentario que sólo condesciende a vivir la aventura de sus intimidades corporales y mentales, funda el universo de Levrero. Ese universo, movido por fuerzas centrípetas mediantes las cuales todo va a parar al "yo" (la literatura de Levrero es una literatura receptiva), tiene zonas que podrían considerarse de marginalidad integrada al conjunto de la obra, como los policiales fantásticos Nick Carter se divierte mientras el lector es asesinado y yo agonizo (1975) y La banda del cienpiés (1989), dos libros en los que la devoción de Levrero por el policial deriva en una descomposición del género que violenta su tradición llevándola a un singular blaxploitation futurista en el que parecen convivir sin problemas la acción directa de Bruce Lee con los decorados de Georges Méliès.

El alma de Gardel reúne todas esas variedades intimistas, que no prescinden de la escena policial, en un mismo espacio de integración atómica que parece presentarse como "lo natural" del estado literario. "Y al fin y al cabo -dice Levrero en una de las pausas reflexivas que sostienen el por qué de su novela-, creo yo, el destino de toda cosa en el universo, tal vez incluso el universo mismo, sea convertirse en Literatura".

\section{AUTORES}

\section{JUAN JOSÉ BECERRA}

Escritor 